\title{
Prognostic value of red blood cell distribution width-standard deviation (RDW-SD) in patients operated on due to non-small cell lung cancer
}

\author{
Mariusz Łochowski ${ }^{1}$, Justyna Chałubińska-Fendler ${ }^{2}$, Barbara Łochowska ${ }^{3}$, Izabela Zawadzka \\ Daniel Brzeziński ${ }^{1}$, Marek Rębowski ${ }^{1}$, Józef Kozak ${ }^{1}$
}

${ }^{1}$ Clinic of Thoracic Surgery and Respiratory Rehabilitation, Medical University of Lodz, Regional Multi-Specialist Center for Oncology and Traumatology of the Nicolaus Copernicus Memorial Hospital in Lodz, Lodz, Poland; ${ }^{2}$ Department of Radiotherapy Military Institute of Medicine, Warsaw, Poland; ${ }^{3}$ Department of Radiotherapy and General Oncology, Regional Multi-Specialist Center for Oncology and Traumatology of the Nicolaus Copernicus Memorial Hospital in Lodz, Lodz, Poland; “"Synevo” Medical Laboratory, Regional Multi-Specialist Center for Oncology and Traumatology of the Nicolaus Copernicus Memorial Hospital in Lodz, Lodz, Poland

Contributions: (I) Conception and design: M Łochowski; (II) Administrative support: M Łochowski, B Łochowska; I Zawadzka; (III) Provision of study materials or patients: M Łochowski, I Zawadzka; (IV) Collection of data: B Łochowska, D Brzeziński; (V) Data analysis and interpretation: M Łochowski, J Chałubińska-Fendler, M Rębowski, J Kozak; (VI) Manuscript writing: All authors; (VII) Final approval of manuscript: All authors. Correspondence to: Mariusz Łochowski. Department of Thoracic Surgery Medical University of Lodz, 62 Pabianicka Str. 93-513 Lodz, Poland.

Email: marilo@op.pl.

Background: The aim of the study was to determine a survival prognostic value of selected blood morphological rates of patients, operated on due to non-small cell lung cancer (NSCLC).

Methods: The study was conducted on 532 patients, surgically treated due to NSCLC, in stages IA-IIIA, 174 females and 358 males, mean age 63.6 years (36-84 years) were included in the study. Blood parameters and clinical factors were included in statistical analysis, in order to determine potential prognostic values of red blood cell distribution width-standard deviation (RDW-SD), mean corpuscular volume (MCV) of red cell and hemoglobin. Factors contained: age, sex, smoking history, histopathological diagnosis , T category, N category, age-adjusted Charlson Comorbidity Index (CCI), number of lymphocytes, neutrophils, monocytes, platelets, the neutrophil to lymphocyte ratio (NLR) and the platelet to lymphocyte ratio (PLR), kind of surgery, patient survival.

Results: The univariate analysis revealed a dependence of the value of RDW-SD and CCI values, the number of monocytes, NLR and PLR values, neoplasia stage and the overall survival. The multivariate analysis confirmed that not only $\mathrm{N} 2$ category and the value of CCI above 4 are negative prognostication factors, but also RDW-SD above $43 \mathrm{fL}(\mathrm{P}=0.00007)$ and PLR above $138(\mathrm{P}=0.001)$ are such negative factors of survival prognosis.

Conclusions: RDW-SD is an independent and significant prognostic factor of patients' survival operated on due to NSCLC.

Keywords: Non-small cell lung cancer (NSCLC); red blood cell distribution width-standard deviation (RDW-SD); patients' survival

Submitted Jul 26, 2019. Accepted for publication Nov 19, 2019.

doi: $10.21037 /$ jtd.2019.12.94

View this article at: http://dx.doi.org/10.21037/jtd.2019.12.94 


\section{Introduction}

Over the past decades, a marked increase in the incidence of malignancies and their mortality has been observed worldwide. Top 10 oncological "killers" include: lung cancer, cervical cancer, breast cancer, colon cancer, gastric cancer, nasopharynx cancer, cancer of the ovary, esophagus, liver and the lymphatic system (1).

Lung cancer, which was a rare disease 100 years ago, is currently the main cause of cancer deaths in men and women. In 2012, over 1.6 million people died of lung cancer in the world. It is estimated that in the year 2035, as many as 3 million people ( 2.1 million men and 0.9 million women) will be affected by this kind of cancer (2). Bearing in mind high incidence of this cancer and poor prognosis, oncological studies focus on a search for markers that would allow to determine the risk of the disease and qualify the patient for appropriate treatment as early as in the diagnostics stage. The search is multidirectional and includes also simple laboratory rates as potential, easily accessible and low-cost prognostic factors. Their increased values may be the response for developing cancer. Recent studies have focused on the relationship between red blood cell distribution width coefficient of variation (RDW-CV) and chronic inflammatory process that is also observed in the course of non-small cell lung cancer (NSCLC). $\mathrm{RDW}-\mathrm{CV}$ is a quantitative parameter which allows to detect changes in the size of circulating erythrocytes in the bloodstream. That is why it is commonly used in diagnosis of various types of anemia $(1,3)$. Recently published studies on RDW-CV and cancers are vividly discussed and the role of RDW-CV as a biomarker is questioned (3). Bearing in mind the above-mentioned reports, we conducted a singlecenter retrospective study and took standard deviation RDW (RDW-SD) into account. RDW-SD enables to determine the ratio of the distribution width and the mean size of a red blood cell (3).

The aim of the study is to evaluate RDW-SD and other blood morphological parameters as prognostic factors in patients surgically treated due to NSCLC.

\section{Methods}

\section{Studied population and patients characteristics}

In period 2007-2014, 1,013 patients were treated surgically due to lung cancer in a single institution (thoracic surgery department located in high volume oncology center in the region). From 1,013 patient treated in the above-mentioned period we included 532 patients into a retrospective analysis. Patients who had undergone wedge resections, segmentectomies or those diagnosed with carcinoid tumor were excluded from the study. The Local Bioethics Committee gave its consent for the study to be conducted (No. RNN/83/19/KE). Before the operation, all the patients had undergone chest computed tomography (CT) and bronchoscopy as well as ultrasound of the abdominal cavity. In the event of lymphadenopathy, the patients underwent positron emission tomography (PET). Lymph nodes were collected via mediastinoscopy and from year 2008, and endobronchial ultrasound (EBUS) examinations were also performed. The patients who did not demonstrate metastases to lymph nodes or in whom the neoplastic process involved only one group of nodes and the nodes were not conglomerated in PET were qualified for the surgery. Upon admission to hospital, all of the patients underwent basic laboratory tests required before the surgery with the use of a hematology analyzer-Sysmex XN 2000. The neutrophil to lymphocyte ratio (NLR, being a ratio of the absolute number of neutrophils and the absolute number of lymphocytes), the platelet to lymphocyte ratio (PLR, identified as a ratio of the absolute number of platelets and the absolute number of lymphocytes), were calculated in all the studied patients.

The study group consisted of 174 females and 358 males with mean age 63.6 years, aged (36-84 years). Over half of $(55 \%)$ of patients admitted to the department were addicted to nicotine. Tumors involved the right lung in 311 patients and the left lung in 221 patients. A histopathological examination confirmed squamous cell carcinoma (in 269 cases), adenocarcinoma (in 204 cases), large cell carcinoma (in 43 cases) and mixed carcinoma (adenosquamous carcinoma-in 16 cases). The majority of patients [375], were categorized into grades 4-6 on the base of the age-adjusted Charlson Comorbidity Index (CCI). The remaining one hundred patients were categorized into grades 2 and 3. Patients characteristic is presented in Table 1.

\section{Surgical treatment}

Anatomical procedures, i.e., lobectomies, bilobectomies and pneumonectomies were performed in all patients with a standard technique, through anterolateral thoracotomy under general anaesthesia with the use of a doublelumen tube. Cefazolin was administered intraoperatively to prevent potential infection. Patients with involvement of the right lung underwent lymphadenectomy of lymph 
Table 1 Patient characteristics

\begin{tabular}{|c|c|c|c|c|}
\hline Parameter & $\mathrm{n}$ & $\%$ & $\begin{array}{c}\text { Median of survival } \\
\text { (years) }\end{array}$ & $P$ value \\
\hline Sex & & & & 0.001 \\
\hline Female & 174 & 33 & 3.42 & \\
\hline Male & 358 & 67 & 3.46 & \\
\hline Smoking & & & & 0.006 \\
\hline Yes & 295 & 55 & 2.36 & \\
\hline No & 237 & 45 & 3.09 & \\
\hline Localization-lung & & & & 0.04 \\
\hline Left & 220 & 41 & 2.42 & \\
\hline Right & 312 & 59 & 2.9 & \\
\hline Localization-lobe & & & & 0.01 \\
\hline Left upper & 119 & 22 & 2.89 & \\
\hline Left lower & 101 & 19 & 1.74 & \\
\hline Right upper & 178 & 34 & 3.01 & \\
\hline Middle & 16 & 3 & 3.71 & \\
\hline Right lower & 118 & 22 & 2.62 & \\
\hline $\mathrm{CCl}$ & & & & 0.0000 \\
\hline 2 & 20 & 4 & & \\
\hline 3 & 80 & 15 & & \\
\hline 4 & 141 & 27 & & \\
\hline 5 & 126 & 24 & $3.76 \leq 4$ & \\
\hline 6 & 108 & 20 & $2.13>4$ & \\
\hline 7 & 43 & 8 & & \\
\hline 8 & 12 & 2 & & \\
\hline 9 & 2 & 0.004 & & \\
\hline
\end{tabular}

$\mathrm{CCl}$, Charlson Comorbidity Index.

nodes of groups: $2 \mathrm{R}, 3 \mathrm{~A}, 4 \mathrm{R}, 7,8,9,10,11$. In the event of involvement of the left lung, lymph nodes of groups: $3 \mathrm{~A}, 4 \mathrm{~L}, 5,6,7,8,9,10,11$ were removed. At least 6 node groups of $\mathrm{N} 1$ and $\mathrm{N} 2$ categories were dissected. The degree of tumor advancement was determined on the basis of the TNM Classification of Malignant Tumors (Union for International Cancer Control, UICC 2017, $8^{\text {th }}$ edition), whereas the collected lymph nodes were classified in compliance with the Naruke map.

\section{Statistical methods}

Particular factors were subjected to a statistical analysis, performed with a view of determining potential prognostic values of RDW-SD, mean corpuscular volume of red cell (MCV) and hemoglobin (HGB). They included: age, sex, smoking, the number of leukocytes, neutrophils, monocytes, platelets, histopathological diagnosis, T category, $\mathrm{N}$ category, CCI, type of surgery, patient survival times.

Continuous variables were verified with the Shapiro-Wilk test for normal distributions. As most data did not meet the normal or similar to normal distribution-non-parametric test were performed. In order to compare two independent groups, the authors applied the U Mann-Whitney test. The Kruskall-Walis test with post-hoc comparisons, with the application of the Dunn-Bonferroni test were used to compare more than two groups. The Chi-square test was applied to calculate nominal variables-as number of observations and percentage values. Correlations-rank, non-parametric-Spearman rank correlation.

The Log-rank test was applied for the purpose of a univariate survival analysis of nominal parameters and Kaplan Mayer curves were drawn. For the purpose of a univariate analysis continuous parameters and multivariate analysis, the authors used the Cox proportional hazard model.

\section{Results}

\section{Surgical treatment and post-operative degree of advancement}

A postoperative histopathological examination revealed stage I in 220 patients (41\%), stage II in 180 patients (34\%) and stage III in 132 patients. Four hundred (75\%) patients underwent lobectomy, 94 (18\%)-pneumonectomy and bilobectomy was performed in 37 (7\%) patients. R0 resection was obtained in all patients. Three patients died postoperatively (one due to perforation of gastric ulcer, one due to a stroke and one due to a myocardial infarction). Complications were observed in 112 (21\%) patients. In most cases, complications showed prolonged air leak (59 patients) and atelectasis which required bronchoscopy (20 patients). Nineteen patients required postoperative transfusion of packed red blood cells concentrate and 10 patients were treated due to a paroxysm of atrial fibrillation (Table 2). 
Table 2 Results of surgical treatment and complications with survival time

\begin{tabular}{|c|c|c|c|c|}
\hline Parameter & $\mathrm{N}$ & $\%$ & $\begin{array}{c}\text { Median of } \\
\text { survival (years) }\end{array}$ & $P$ value \\
\hline \multicolumn{5}{|l|}{ Diagnosis } \\
\hline Squamous cell carcinoma & 269 & 50 & 2.84 & 0.7 \\
\hline Adenocarcinoma & 204 & 38 & 2.39 & \\
\hline Large cell carcinoma & 42 & 8 & 2.83 & \\
\hline Mixed type carcinoma & 16 & 4 & 2.14 & \\
\hline Stage of the disease & & & & 0.0000 \\
\hline $\mathrm{T} \mid \mathrm{A} 1$ & 3 & 1 & 7.37 & \\
\hline T IA2 & 40 & 8 & 7.48 & \\
\hline T IA3 & 39 & 8 & 5.39 & \\
\hline $\mathrm{T}$ IB & 138 & 25 & 3.27 & \\
\hline $\mathrm{T} \| \mathrm{A}$ & 8 & 2 & 0.78 & \\
\hline $\mathrm{T} \| \mathrm{B}$ & 172 & 32 & 2.08 & \\
\hline $\mathrm{T} I \mathrm{IIA}$ & 132 & 24 & 1.81 & \\
\hline \multicolumn{5}{|l|}{ Surgical treatment } \\
\hline Lobectomy & 400 & 75 & 2.73 & 0.004 \\
\hline Bilobectomy & 37 & 7 & 3.49 & \\
\hline Pneumonectomy & 94 & 18 & 1.67 & \\
\hline \multicolumn{5}{|l|}{ Complications } \\
\hline All complications & 112 & 21 & 2.11 & 0.004 \\
\hline Prolonged air leak & 59 & & & \\
\hline Atelectasis & 20 & & & \\
\hline Postoperative transfusion & 19 & & & \\
\hline Atrial fibrillation & 10 & & & \\
\hline Bronchia fistula & 2 & & & \\
\hline Pleural empyema & 1 & & & \\
\hline Pneumonia & 1 & & & \\
\hline
\end{tabular}

\section{Overall survival (OS) of patients}

The mean OS was 50 months. Four hundred and 6 (76\%) patients survived 1 year, $304(57 \%)$ patients survived 2 years, 245 (46\%) patients survived 3 years and 185 (35\%) patients survived 4 years. Females and male non-smokers lived significantly longer (4.87 vs. 3.91 years; $\mathrm{P}=0.00117$ ) and (4.63 vs. 3.88 years; $\mathrm{P}=0.006$, respectively). The patients' survival depended on the degree of advancement of neoplastic disease and a particular type of surgical intervention: survival was longer in patients with stage $\mathrm{N} 0$ than in those with stages $\mathrm{N} 1$ and N2 (the medians respectively: 3.38 vs. 2.28 vs. 1.28 years; $\mathrm{P}=0.0000)$; patients with stages $\mathrm{T} 1$ and $\mathrm{T} 2$ lived longer than those with stages $\mathrm{T} 3$ and $\mathrm{T} 4(\mathrm{P}=0.0009)$; patients, who underwent pneumonectomy lived significantly shorter than patients after lobectomy or bilobectomy (the medians respectively: 1.67 vs. 2.73 and 3.49 years; $\mathrm{P}=0.0046$; Figure $1 A, B, C, D, E$; Table 2). For CCI, the authors calculated the Receiver Operating Characteristic (ROC) and determined the maximum values of sensitivity and specificity of the studied parameter. This was a ground for calculating the optimal value of the studied parameter. It was 4 for CCI. The lifespan of patients with CCI value above 4 was significantly shorter (5.02 vs. 3.55 years; $\mathrm{P}=0.0000$; Figure $1 F$, Figure $2 A$ ). Tumor localization (right lung/left lung; a particular lobe) demonstrated a statistical significance and did not significantly affect survival (respectively $\mathrm{P}=0.048 ; \mathrm{P}=0.01$ ). A histopathological type of cancer did not have a significant effect on the lifespan $(\mathrm{P}=0.7)$.

\section{RDW as a prognostic factor}

In order to optimally determine limit values of RDWSD, MCV and HGB as well as PLR and NLR, receiver operating characteristic (ROC) curves were used. The area under the curve (AUC) values for RDW-SD, MCV and HGB were respectively: 0.576 (95\% CI: 0.521-0.6331, $\mathrm{P}=0.007$ ), 0.532 (95\% CI: 0.481-0.592, $\mathrm{P}=0.25$ ) and 0.557 (95\% CI: $0.507-0.607, \mathrm{P}=0.0264$ ). The optimal limit value for RDW-SD was $43 \mathrm{fL}$, for MCV-89.5 fL, for HGB$13.2 \mathrm{~g} / \mathrm{dL}$ (Figure $2 B, C, D$ ). For PLR and NLR, the AUC was respectively: 0.587 (95\% CI: $0.531-0.642, \mathrm{P}=0.0024$ ); 0.567 (95\% CI: $0.509-0.624, \mathrm{P}=0.0238$ ). The optimal value for PLR-138 and for NLR was 235 (Figure 2E,F).

Statistical analysis revealed a significantly longer $(\mathrm{P}=0.0096)$ survival of the patients in whom RDW-SD values were below $43 \mathrm{fL}$ (medians and $\mathrm{P}$ values are shown on Figure 3).

A study showed a negative correlation between RDW$\mathrm{SD}$ and the number of monocytes and an increased PLR ratio. Negative correlation was also found between $\mathrm{MCV}$ and the number of platelets and neutrophils as well as PLR and NLR. With regards to HGB, there was a negative correlation between the number of monocytes and platelets (all $\mathrm{R}$ values are shown in Table 3). Taking clinical and pathological factors into account, the authors 

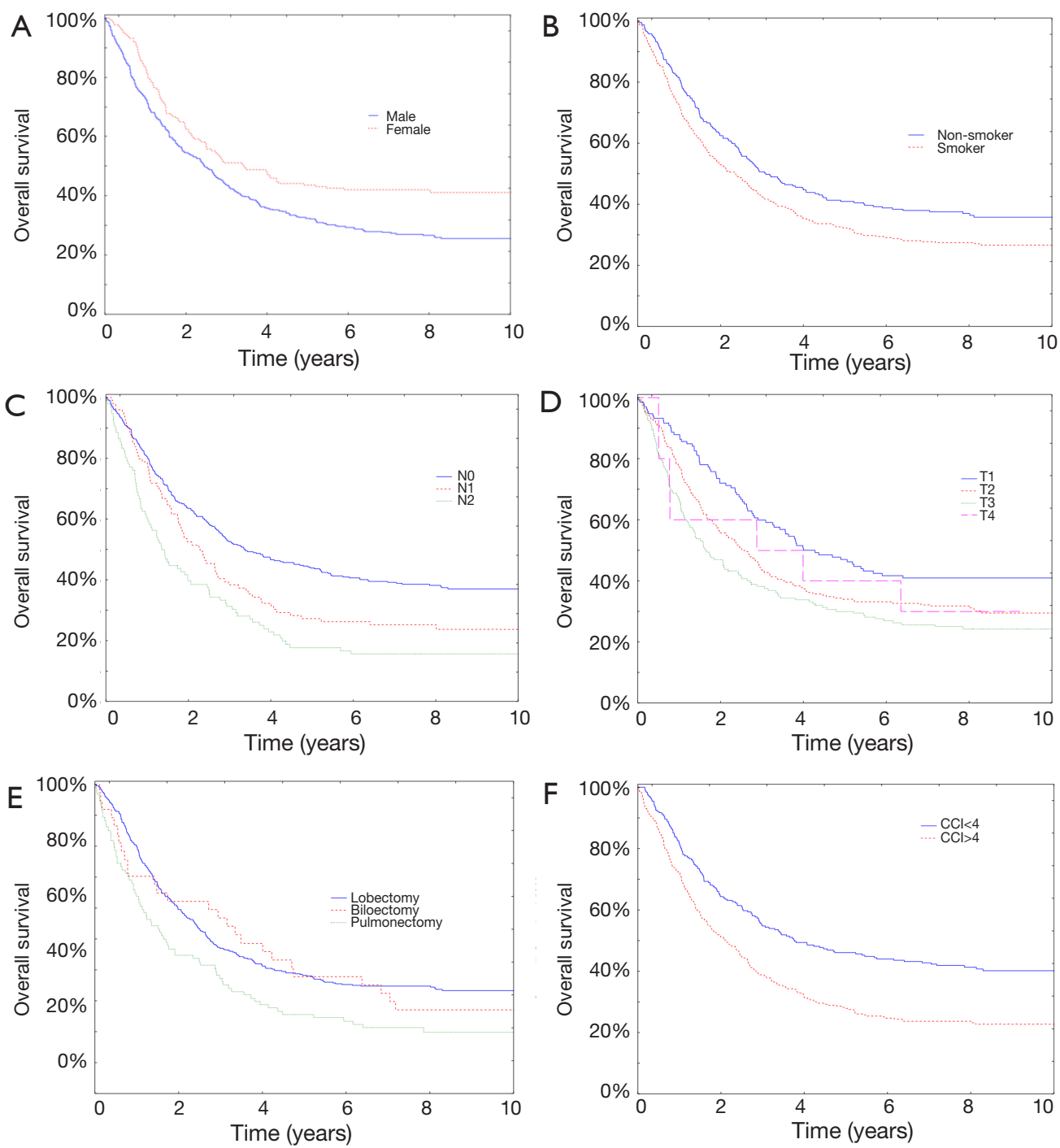

Figure 1 Kaplan-Meier curves of survival of patients operated on due to non-small cell lung cancer (NSCLC) for (A) sex, (B) smoking, (C) $\mathrm{N}$ stage, (D) T stage, (E) type of procedure, (F) Charlson Comorbidity Index (CCI) index.

revealed a negative correlation between RDW-SD and the advancement stage of the disease (all $\mathrm{P}$ and $\mathrm{R}$ values are shown in Table 4).

A univariate analysis showed significant dependence between the RDW-SD value, the number of monocytes, PLR and NLR ratios and CCI and the overall survival of the patients (all $\mathrm{P}$ and $\mathrm{R}$ values are shown in Table 5).

A multivariate analysis showed that the advancement stage of neoplasia, CCI above 4, RDW-SD values above $43 \mathrm{fL}(\mathrm{P}=0.0007)$ and PLR values above $138(\mathrm{P}=0.001)$ should be considered negative prognostic factors for patients operated on due to NSCLC (all P and R values are shown in Table 6).

\section{Discussion}

Clinical studies showed significant differences in RDW values in patients treated for various cancers in comparison to healthy subjects or treated for non-cancer conditions such as heart failure and chronic obstructive pulmonary disease (4-6). The prognostic value of RDW-CV was confirmed in ovarian cancer, colon cancer and hematological diseases (79). In our study, we focused on the prognostic role of RDW$\mathrm{SD}$ in patients surgically treated due to NSCLC. Value 

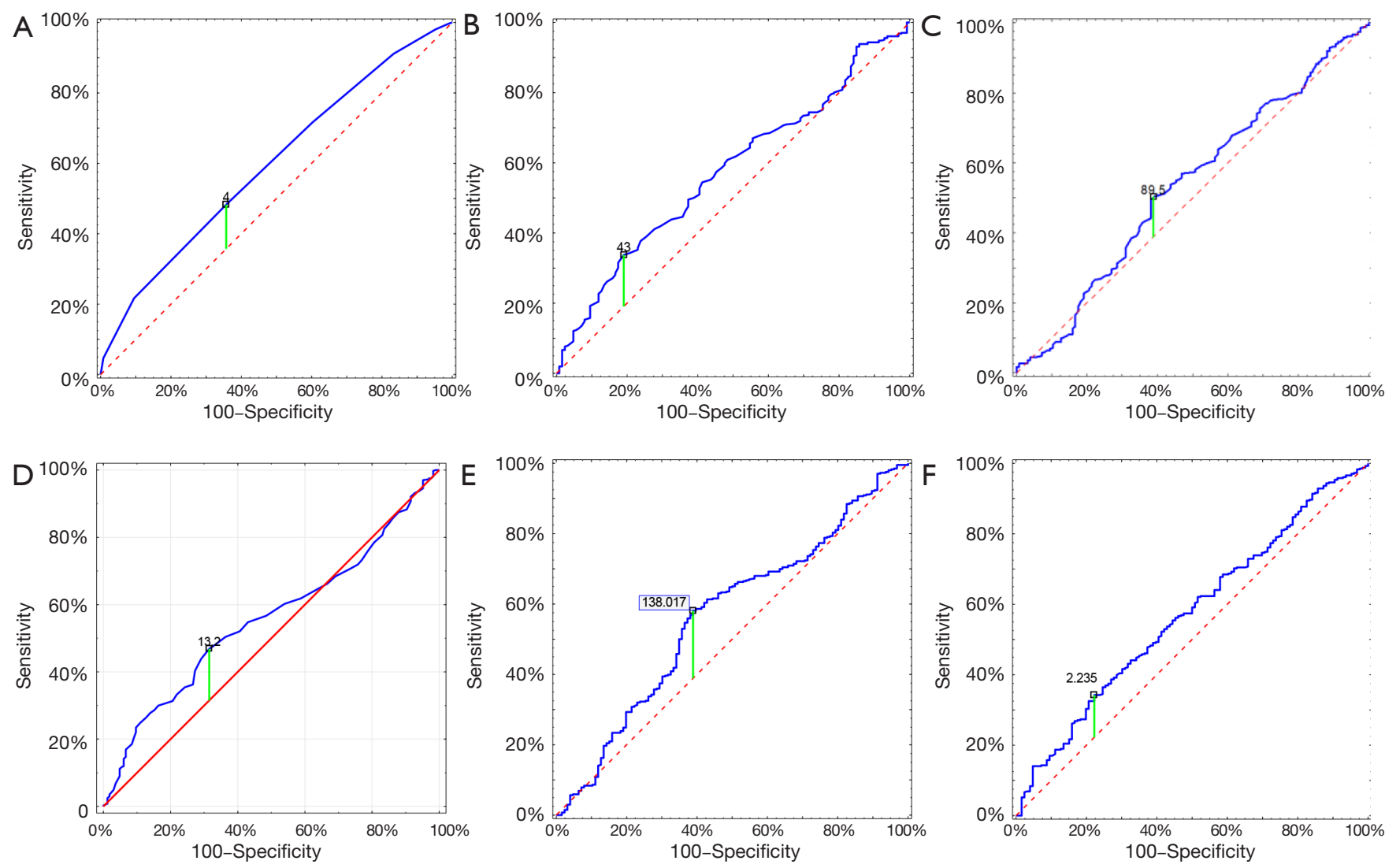

Figure 2 Youden index with receiver operating characteristic (ROC) curves. (A) Charlson Comorbidity Index (CCI); (B) red blood cell distribution width-standard deviation (RDW-SD); (C) mean corpuscular volume (MCV); (D) hemoglobin (HGB); (E) platelet to lymphocyte ratio (PLR); (F) neutrophil to lymphocyte ratio (NLR).

of our study is limited as it was conducted in one centre and it is retrospective. Only patients who met criteria of operability were included in the study. Therefore, the selection bias should be taken into account while interpreting these results. Our analysis showed that RDW-SD is an independent prognostic factor for patients treated in our department due to NSCLC. Studies conducted so far took into account the role of RDW-CV as a prognostic factor for NSCLC. Koma et al. revealed that elevated $\mathrm{RDW}-\mathrm{CV}$ values $(>15 \%)$ are associated with worse prognosis of patients with NSCLC $(\mathrm{P}=0.002)(10)$. In another study, Kos et al. did not confirm this observation. However, the authors themselves stated that the negative result, obtained in their study, might be related to an insufficient number of patients [146] included in the analyses (4). Warwick et al. based their study on 917 patients treated surgically due to NSCLC. Those authors observed that preoperative $\mathrm{RDW}-\mathrm{CV}$ values above $15.3 \%$ are a significant risk factor of post-operative mortality $(\mathrm{P}=0.001)$ and survival period ( $\mathrm{P}=0.0001)$ (11). Ichinose et al. analyzed an equally large group (992 patients). His study showed that in NSCLC patients above 75 years of age, pre-operative RDW-CV value above $15 \%$ is associated with a higher risk of complications and worse prognosis $(\mathrm{P}=0.01)(12)$.

The relationship between elevated RDW values and unfavorable course of neoplastic disease is not clear. Relatively large reticulocytes that increase the RDW value occur in long-term anemia. Those results may also be a consequence of a long-lasting inflammatory process, being the body response to cancer, bone marrow dysfunction or iron deficiency (9). We did not determine the level of vitamin B12, folic acid and iron in our patients, which might be another limitation and could have and impact on bold test results. In our study, we showed a correlation between increased RDW-SD values and the number of peripheral monocytes and the PLR value. A multi-factor analysis revealed that in addition to RDW-SD, PLR values above 


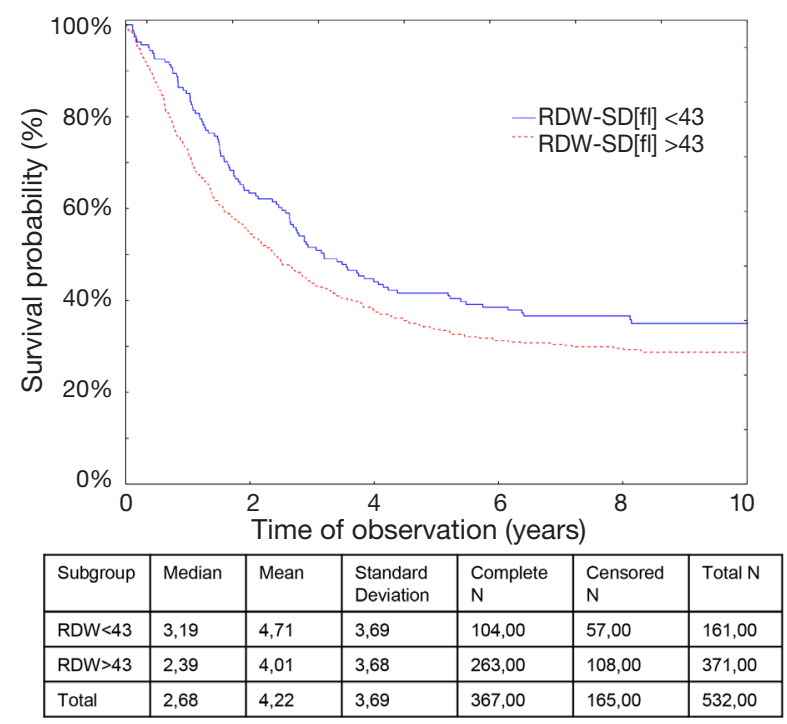

Figure 3 Kaplan-Meyer curves for RDW $>43$ and $<43$; log rank test $\mathrm{P}=0.00966$. RDW, red blood cell distribution width.
138 are a significant and independent prognostic factor of NSCLC. This indicates an association of the studied parameter with chronic inflammatory reaction. Kumagai et al. noted that an increased number of monocytes may be an independent prognostic factor and affects the OS of patients surgically treated due to pulmonary adenocarcinoma (13). In turn, Lee et al. showed that PLR values above 180 significantly affect OS (14). Our analysis, however, did not show a correlation between RDW-SD and the number of lymphocytes, neutrophils, platelets and the NLR ratio. The obtained results point unclear interactions between inflammation and RDW indicators, and the mechanisms themselves require further investigation.

The advantage of RDW as a possible prognostic marker in NSCLC is a simple procedure of the test, high availability, low price and short period of time required to obtain result (12).

In our opinion, RDW-SD can be considered an

Table 3 Spearman rank correlation $\mathrm{R}$ values matrix bold $\mathrm{R}$ are significant correlations with $\mathrm{P}$ values $<0.05$

\begin{tabular}{lccccccccc}
\hline Parameter & MCV (fL) & $\begin{array}{c}\text { RDW-SD } \\
(\mathrm{fL})\end{array}$ & $\begin{array}{c}\mathrm{HGB} \\
(\mathrm{g} / \mathrm{dL})\end{array}$ & Neutrophils $\left(10^{3}\right)$ & Lymphocytes $\left(10^{3}\right)$ & Monocytes $\left(10^{3}\right)$ & Platelets $\left(10^{3}\right)$ & NLR & PLR \\
\hline MCV (fL) & 1.00 & 0.45 & 0.04 & -0.09 & 0.07 & -0.04 & -0.16 & -0.14 & -0.20 \\
RDW-SD (fL) & 0.45 & 1.00 & 0.03 & 0.00 & 0.08 & -0.13 & -0.03 & -0.03 & -0.09 \\
HGB (g/dL) & 0.04 & 0.03 & 1.00 & -0.06 & -0.02 & -0.11 & -0.09 & -0.01 & -0.03 \\
\hline
\end{tabular}

MCV, mean corpuscular volume; RDW-SD, red blood cell distribution width-standard deviation; HGB, hemoglobin; NLR, neutrophil to lymphocyte ratio; PLR, platelet to lymphocyte ratio.

Table 4 Red blood cell distribution width-standard deviation associations with clinicopathological factors with $\mathrm{P}$ values

\begin{tabular}{|c|c|c|c|c|c|c|}
\hline Parameter & R spearman & $P$ value & U test value & $P$ value & Wallis $\mathrm{H}$ value & $P$ value \\
\hline RDW-SD (fL) \& CCl & -0.0548 & 0.206 & & & & \\
\hline \multicolumn{7}{|l|}{ U-Mann tests } \\
\hline RDW-SD (fL) \& sex & & & $29,641.5$ & 0.360 & & \\
\hline RDW-SD (fL) \& smoking & & & $33,270.0$ & 0.138 & & \\
\hline RDW-SD (fL) \& complications & & & $23,068.5$ & 0.602 & & \\
\hline RDW-SD (fL) \& pathology type & & & $32,911.0$ & 0.752 & & \\
\hline \multicolumn{7}{|l|}{ Kruskall Wallis ANOVA } \\
\hline RDW-SD (fL) \& N & & & & & 3.209 & 0.200 \\
\hline
\end{tabular}

RDW-SD, red blood cell distribution width-standard deviation. 
Table 5 Results of studied parameters and single-factor analysis in patients operated on due to NSCLC

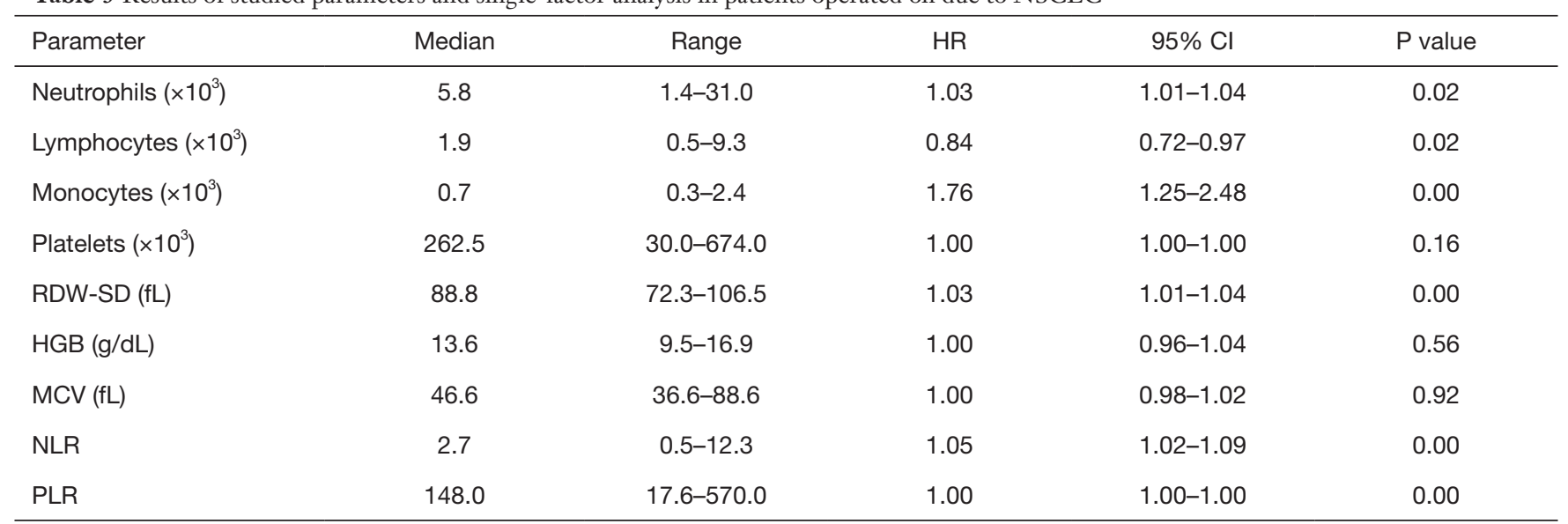

NSCLC, non-small cell lung cancer; RDW-SD, red blood cell distribution width-standard deviation; HGB, hemoglobin; MCV, mean corpuscular volume; NLR, neutrophil to lymphocyte ratio; PLR, platelet to lymphocyte ratio; CCI, Charlson Comorbidity Index.

Table 6 Multi-variate analysis in patients operated on due to NSCLC

\begin{tabular}{llll}
\hline Parameter & HR & $95 \% \mathrm{Cl}$ & P value \\
\hline Neutrophils $\left(\times 10^{3}\right)$ & 1.145 & $0.986-1.331$ & 0.075 \\
Lymphocytes $\left(\times 10^{3}\right)$ & 1.137 & $0.643-2.012$ & 0.656 \\
Monocytes $\left(\times 10^{3}\right)$ & 1.735 & $0.404-7.443$ & 0.458 \\
Platelets $\left(\times 10^{3}\right)$ & 0.997 & $0.992-1.002$ & 0.366 \\
RDW-SD $>43(\mathrm{fL})$ & 0.908 & $0.865-0.952$ & 0.00007 \\
HGB $(\mathrm{g} / \mathrm{dL})$ & 0.962 & $0.901-1.027$ & 0.248 \\
NLR $>2.23$ & 0.947 & $0.713-1.395$ & 0.988 \\
PLR $>138$ & 0.994 & $0.991-0.997$ & 0.001 \\
CCI $>4$ & 0.371 & $0.247-0.493$ & 0.00008 \\
Stage & 0.217 & $0.096-0.833$ & 0.00003 \\
\hline
\end{tabular}

NSCLC, non-small cell lung cancer; RDW-SD, red blood cell distribution width-standard deviation; HGB, hemoglobin; NLR, neutrophil to lymphocyte ratio; PLR, platelet to lymphocyte ratio; $\mathrm{CCl}$, Charlson Comorbidity Index.

independent prognostic factor in NSCLC. The multifactorial OS model shows that the survival of patients with NSCLC is determined by increased RDW-SD values above 43, PLR values above 138, particular advancement stage of the disease and comorbidities burden expressed by the CCI above 4.

\section{Acknowledgments}

Funding: None.

\section{Footnote}

Conflicts of Interest: The authors have no conflicts of interest to declare.

Ethical Statement: The authors are accountable for all aspects of the work in ensuring that questions related to the accuracy or integrity of any part of the work are appropriately investigated and resolved. The Local Bioethics Committee gave its consent for the study to be conducted (No. RNN/83/19/KE).

Open Access Statement: This is an Open Access article distributed in accordance with the Creative Commons Attribution-NonCommercial-NoDerivs 4.0 International License (CC BY-NC-ND 4.0), which permits the noncommercial replication and distribution of the article with the strict proviso that no changes or edits are made and the original work is properly cited (including links to both the formal publication through the relevant DOI and the license). See: https://creativecommons.org/licenses/by-nc-nd/4.0/.

\section{References}

1. Li J, Yang X, Ma J, et al. Relationship of Red blood cell distribution width with cancer mortality in hospital. Biomed Res Int 2018;2018:8914617.

2. Didkowska J, Wojciechowska U, Mańczuk M, et al. Lung cancer epidemiology: contemporary and future challenges worldwide. Ann Transl Med 2016;4:150.

3. Hu L, Li M, Ding Y, et al. Prognostic value of RDW in 
cancers: a systemic review and meta-analysis. Oncotarget 2017;8:16027-35.

4. Kos M, Hocazade C, Kos FT, et al. Evaluation of the effects of red blood cell distribution width on survival in lung cancer patients. Contemp Oncol (Pozn) 2016;20:153-7.

5. Seretis C, Seretis F, Lagoudianakis E, et al. Is red cell distribution width a novel biomarker of breast cancer activity? Data from a pilot study. J Clin Med Res 2013;5:121-6.

6. Seyhan EC, Özgül MA, Tutar N, et al. Red blood cell distribution and survival in patients with chronic obstructive pulmonary disease. COPD 2013;10: 416-24.

7. Qui Y, Wang P, Huang Z, et al. The value of red cell distribution width in patients with ovarian cancer. Medicine (Balitmore) 2017;96:e6752.

8. Li Y, Xing C, Wei M, et al. Combining red blood cell distribution width (RDW-CW) and CEA predict poor prognosis for survival outcomes in colorectal cancer. J Cancer 2019;10:1162-70.

9. Ai L, Mu S, Hu Y. Prognostic role of RDW in hematological malignances: a systematic review and meta-

Cite this article as: Łochowski M, Chałubińska-Fendler J, Łochowska B, Zawadzka I, Brzeziński D, Rębowski M, Kozak J. Prognostic value of red blood cell distribution width-standard deviation (RDW-SD) in patients operated on due to non-small cell lung cancer. J Thorac Dis 2020;12(3):773-781. doi: 10.21037/ jtd.2019.12.94 analysis. Cancer Cell Int 2018;18:61.

10. Koma Y, Onishi A, Matsuoka H, et al. Increased red blood cell distribution width associates with cancer stage and prognosis in patients with lung cancer. PLoS One 2013;8:e80240.

11. Warwick R, Mediratta N, Shackcloth M, et al. Preoperative red cell distribution width in patients undergoing pulmonary resections for non-small-cell lung cancer. Eur J Cardiothorac Surg 2014;45:108-13.

12. Ichinose J, Murakawa T, Kawashima M, et al. Prognostic significance of red cell distribution width in elderly patients undergoing resection for non-small lung cancer. J Thorac Dis 2016;8:3658-66.

13. Kumagai S, Marumo S, Shoji T et al. Prognostic impact of preoperative monocyte counts inpatients with resected lung adenocarcinoma. Lung Cancer 2014;85:457-64.

14. Lee MB, Rodrigeuz A, Mena G, et al. Platelet-tolymphocyte ratio and use of NSIADs during perioperative period as prognostic indicators in patients with NSCLC undergoing surgery. Cancer Control 2016;23:284-94. 